\title{
Analysis of corrosion perforation of a gas gathering carbon steel pipeline in a western oilfield in China
}

\author{
Juntao Yuan ${ }^{1, \text { a }}$, Huihui Zhang ${ }^{2}$, Ke Tong ${ }^{1}$, Fagen $\mathrm{Li}^{1}$, Yan Long ${ }^{1}$, Lei $\mathrm{Li}^{1}$ \\ ${ }^{1}$ CNPC Tubular Goods Research Institute, Xi'an 710077, China; \\ ${ }^{2}$ College of Materials Science and Engineering, Xi'an University of Science and Technology, Xi'an 710058, China
}

\begin{abstract}
In the west of China, corrosion perforation and scaling of pipelines occur frequently in the ground gathering system in oil and gas field, and cause serious safety and environmental problems. In the present work, the corrosion perforation of a carbon steel pipeline with a grade of 20 in a western oil field in China was investigated. Optical metallographic microscopy, scanning electron microscopy (SEM), energy dispersive spectroscopy (EDS), and X-ray diffraction were used to determine the most probable causes of the corrosion perforation. The results showed that the internal corrosion of the studied carbon steel pipe was ascribed to the corrosive $\mathrm{CO}_{2}$ gas and the high content of formation water in the internal transporting medium. The formation of loose and porous iron carbonate layer and the scaling layer with poor adhesion could not protect the carbon steel effectively, so that the high concentration of chloride ions in the formation water caused the initiation of localized corrosion possibly by changing the solubility of iron carbonate, and then the localized corrosion pit propagated and eventually caused the perforation.
\end{abstract}

Keywords: corrosion perforation; scaling; failure analysis; pipeline; carbon dioxide.

\section{Introduction}

With the continuously growing demand in oil and gas energy globally, the search for new sources of oil and gas makes the operation condition became more and more severe [1]. In west China, with the increase of dosage of chemical in the crude oil exploitation process, $\mathrm{pH}$ value of the produced oil decreases and salinity increases, therefore, the corrosion rate of oil pipeline accelerates sharply, and the corrosion mechanism also becomes much more complicated [2]. Corrosion perforation and scaling occur frequently in surface gathering pipeline of western oil field in China in recent years, and this problem seriously affects the safe production of oil field. On the one hand, uniform corrosion induced by acid gas such as $\mathrm{CO}_{2}$ and $\mathrm{H}_{2} \mathrm{~S}$ results in the thinning of pipeline and then reduces its pressure bearing capacity. On the other hand, localized corrosion such as pitting corrosion and mesa attack possibly induced by high content of erosive anions such as chloride ions results in corrosion perforation and then causes serious environmental pollution and great economic loss [3]. However, the cause of corrosion failure is still not clear due to the complicated working conditions in the western oil filed in China.

Recently, corrosion perforation occurred in a carbon steel pipeline with a grade of 20 which was utilized in the ground gathering system in a western oil field in China, and caused safety accident. In

a Corresponding author : yuanjuntaolly@163.com 
the present work, we analyzed this perforated carbon steel pipe carefully by macro/micro investigation, chemical analysis, and phase identification; and then proposed the failure causes for the corrosion perforation.

\section{Experimental}

The failed carbon steel pipe under investigation was subjected to the following procedures to assess corrosion attack.

\subsection{Visual examination of inner and outer surfaces}

The inner and outer surface of the perforated pipe was examined visually, the amount of the obvious corrosion pits was investigated, and the typical macro morphology was taken using the camera (NIKON L100). Then the sample pieces comprising the perforated carbon steel pipe were cut from the corresponding parts based on the requirements of the different tests.

\subsection{Composition, metallographic structure tests}

The chemical compositions of perforated carbon steel pipe were analyzed by a direct reading spectrometer (ARL 4460) on the basis of GB/T 4336-2002. The metallographic structure and inclusions were analyzed by optical metallographic microscopy (MEF4M) based on GB/T 13298-1991, GB/T 10561-2005 and GB/T 6394-2002.

\subsection{SEM examination of the corroded surfaces and scaling}

Morphologies of the corrosion films were investigated using a Scanning Electron Microscopy (SEM, Philips XL-30), and chemical compositions of the surface films were analyzed by Energy Dispersion Spectrum (EDS, INCA). Phases of the corrosion products were identified using an X-ray Diffractometer (XRD, D8 ADVANCE) with filtered $\mathrm{Cu}$ k $\alpha$ radiation.

\section{Results and discussion}

\subsection{Visual inspection}

Figure 1 shows the outer appearance of the perforated carbon steel pipe. On the outside surface of the pipe, the red anticorrosive paint and white insulation layer can be observed. In addition, a corrosion pore with a diameter of $\sim 8 \mathrm{~mm}$ can be seen in Figure 1. Near the corrosion pore, the red anticorrosive paint dropped locally and slight corrosion can be seen.

Figure 2 presents the internal appearance of the perforated carbon steel pipe. There are several characteristic features. First, a wide-range area of corrosion thinning can be seen around the corrosion pore. The largest size of the corrosion pits is $120 \mathrm{~mm} \times 40 \mathrm{~mm}$. Second, significant exfoliation of corrosion products can be seen. Figure 3 shows the appearance of the spalled corrosion layer. 

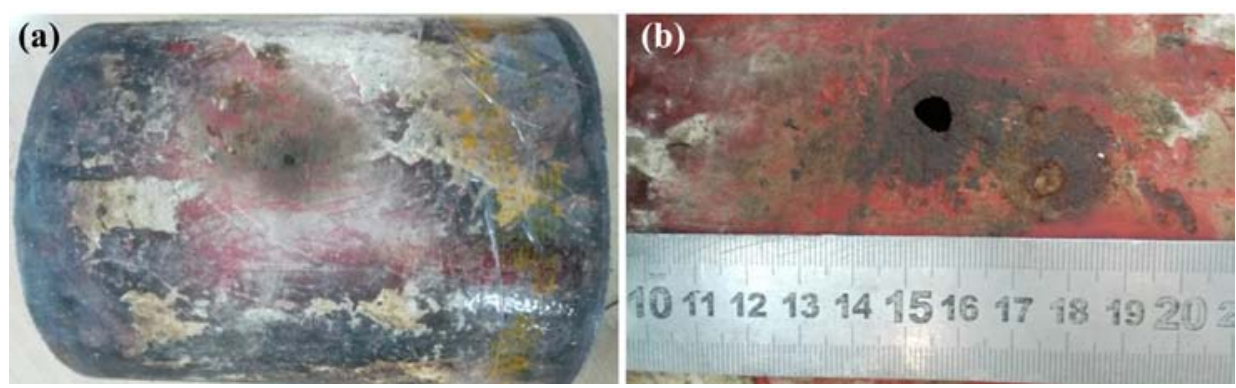

Figure 1. The outside appearance of the corroded carbon steel pipe

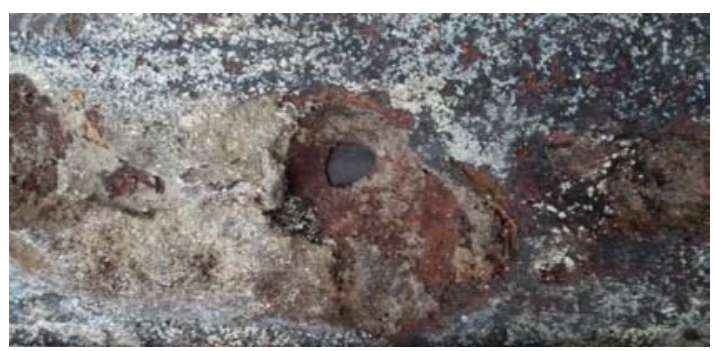

Figure 2. The internal appearance of the corroded carbon steel pipe

(a)

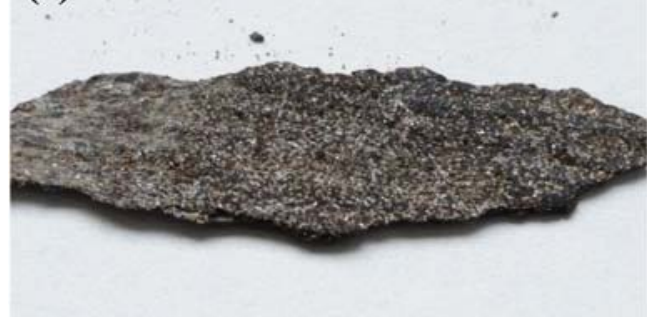

(b)

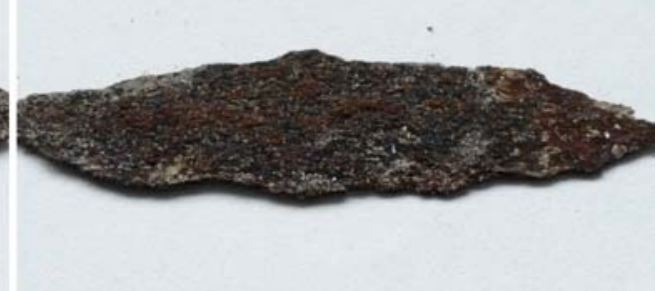

Figure 3. Macro appearances of the corrosion layer: (a) the outer surface, and (b) the inner surface

\subsection{Composition test of carbon steel pipe}

The chemical compositions of the carbon steel pipe are shown in Table 1, which is compared with the parameter requirements of GB/T 699-1999 standard. The results showed that the contents of C, Si, Mn, $\mathrm{P}, \mathrm{S}, \mathrm{Cr}, \mathrm{Ni}$, and $\mathrm{Cu}$ all meet the technical requirements of $\mathrm{GB} / \mathrm{T}$ 699-1999.

Table 1. Chemical compositions of the corroded carbon steel pipe (wt.\%)

\begin{tabular}{|c|c|c|c|c|c|c|c|c|c|}
\hline Element & $\mathrm{C}$ & $\mathrm{Si}$ & $\mathrm{Mn}$ & $\mathrm{P}$ & $\mathrm{S}$ & $\mathrm{Cr}$ & $\mathrm{Ni}$ & $\mathrm{Cu}$ & $\mathrm{Fe}$ \\
\hline $\begin{array}{c}\text { Carbon } \\
\text { steel pipe }\end{array}$ & 0.20 & 0.27 & 0.49 & 0.0088 & 0.0081 & 0.020 & 0.018 & 0.043 & Bal. \\
\hline $\begin{array}{c}\mathrm{GB} / \mathrm{T} \\
699-1999\end{array}$ & $0.17 \sim 0.23$ & $0.17 \sim 0.37$ & $0.35 \sim 0.65$ & $\leq 0.035$ & $\leq 0.035$ & $\leq 0.25$ & $\leq 0.30$ & $\leq 0.25$ & Bal. \\
\hline
\end{tabular}

\subsection{Light optical microscopy}

Table 2 lists the results of metallographic microstructure, grain size and non metal inclusions of the perforated carbon steel pipe. It indicates that the metallographic structure of the carbon steel pipe is ferrite (shown in Figure 4a), the grain grade is 6.0, and the inclusions are A0.5, B0.5, D1.5, and D0.5e. For the specimen containing the corrosion perforation, its metallographic structure is ferrite with no 
significant deformation, while some corrosion products is visible in the corrosion pore as shown in Figure $4 \mathrm{~b}$.

Table 2. Results of metallographic analysis

\begin{tabular}{|c|c|c|c|}
\hline Specimen & $\begin{array}{c}\text { Metallographic } \\
\text { structure }\end{array}$ & Grain grade & Non metal inclusions \\
\hline $\mathrm{NF}^{\mathrm{a}}$ specimen & Ferrite & 6.0 & $\begin{array}{c}\mathrm{A} 0.5, \mathrm{~B} 0.5, \mathrm{D} 1.5, \\
\mathrm{D} 0.5 \mathrm{e}\end{array}$ \\
\hline $\mathrm{CP}^{\mathrm{b}}$ specimen & Ferrite & $\mathrm{ND}^{\mathrm{c}}$ & $\mathrm{ND}^{\mathrm{c}}$ \\
\hline $\begin{array}{l}\text { a. NF represents the Non Failed specimen. } \\
\text { b. } \mathrm{CF} \text { represents the specimen containing corrosion pore. } \\
\text { c. ND represents the issue are not detected in the present work. }\end{array}$ \\
\hline
\end{tabular}

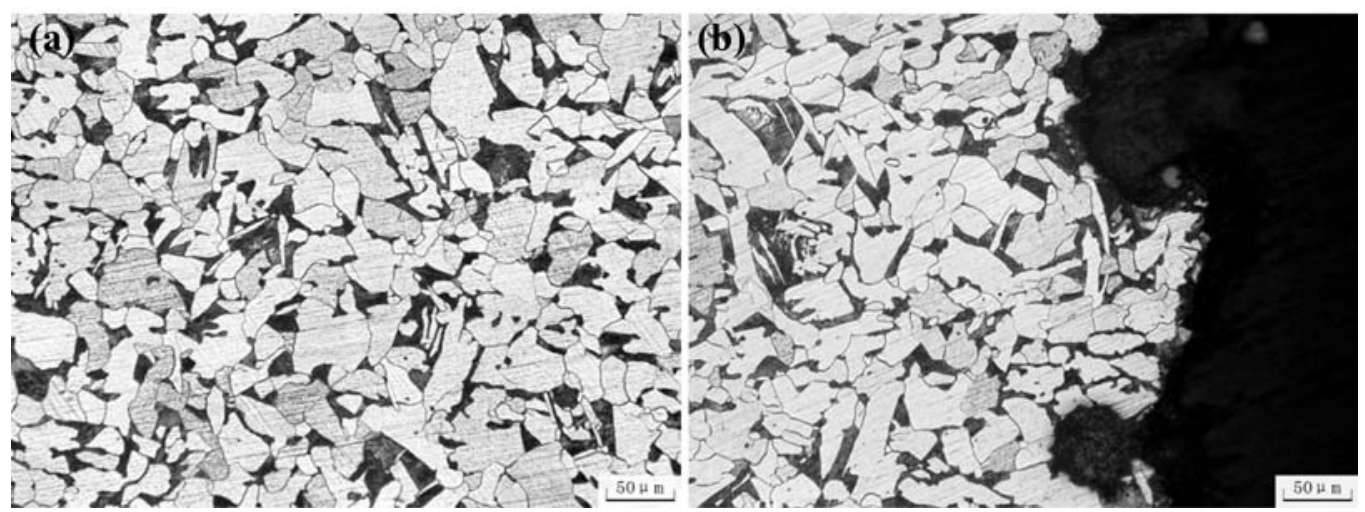

Figure 4. Microstructures of the (a) NF specimen and (b) CP specimen

\subsection{Scanning electron microscopy}

Three coupons were cut from the perforated carbon steel pipe and were used to investigate the microstructure by SEM and analyze the chemical compositions by EDS. No. 1 specimen was cut from the region near to the corrosion pore. No.2 specimen was cut from the region far away from the corrosion pore. No. 3 specimen was cut from the region nearby the corrosion pore and prepared as cross-section specimen.

Figure 5 presents the surface morphologies of the No. 1 specimen. On the bottom of the corrosion pit, several small pits make the surface rough enough (Figure 5a), and EDS analysis indicates the high content of $\mathrm{C}, \mathrm{O}, \mathrm{Fe}$, as well as some content of $\mathrm{S}$ and $\mathrm{Cl}$. In the region outside of the corrosion pit, evident exfoliation can be seen in Figure 5b. EDS analysis indicates that the chemical compositions are similar to those in the bottom of the corrosion pit.

Figure 6 shows the surface morphologies of the No. 2 specimen. Far away from the corrosion pit, the corrosion products seem dense, however, exfoliation is still evident. EDS analysis indicates that the similar chemical compositions as above. 


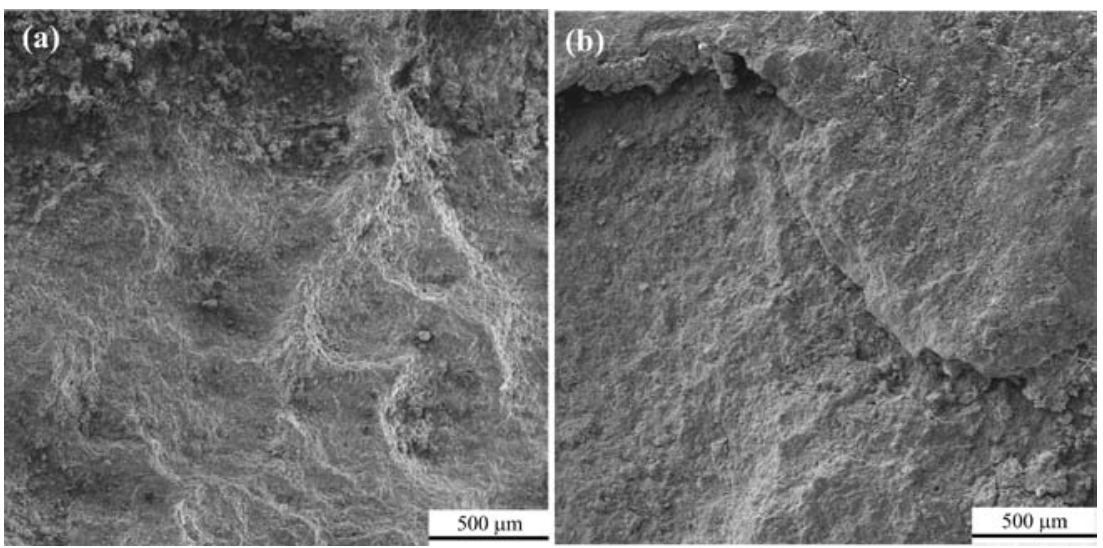

Figure 5. Surface morphologies of the No.1 specimen in the region of (a) the bottom of the corrosion pit and (b) the plat area near to the corrosion pit

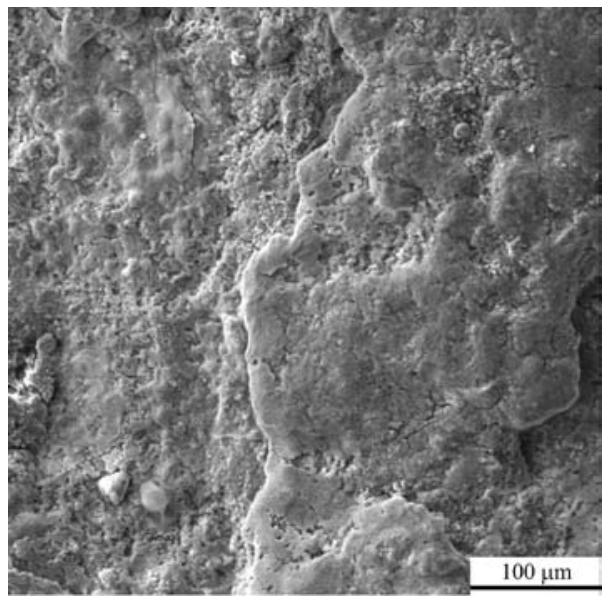

Figure 6. Surface morphology of the No.2 specimen

Figure 7 presents the cross section morphology of corrosion pit. Several small pits can be observed, which is in accordance with the observation from surface morphology as shown in Figure 5a. EDS analysis implies that the chemical compositions are similar to the corrosion products in others, except for the small content of $\mathrm{Ca}$.

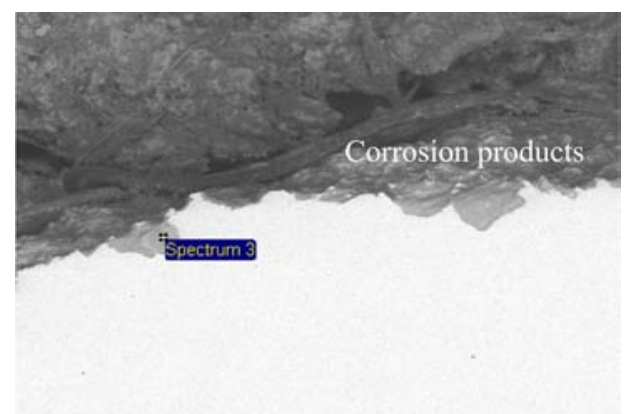

Steel

Figure 7. Cross section morphology of the corrosion pit (No. 3 specimen) 


\subsection{Phase identification of corrosion products}

Figure 8 shows the XRD spectrum diagrams of the corrosion products, where the outer corrosion products were made from the exfoliated corrosion layers as shown in Figure 3 and the internal corrosion products were taken from the region where surface products spalled. It can be seen that the outer corrosion products are composed of $(\mathrm{Ca}, \mathrm{Mg}) \mathrm{CO}_{3}, \mathrm{BaCO}_{3}, \mathrm{FeCO}_{3}$ and $\mathrm{SrSO}_{4}$, and the internal corrosion products consists of $\mathrm{FeCO}_{3}, \mathrm{FeO}(\mathrm{OH})$ and $\mathrm{Fe}_{2} \mathrm{O}_{3}$. The formation of insoluble salts such as $(\mathrm{Ca}, \mathrm{Mg}) \mathrm{CO}_{3}, \mathrm{BaCO}_{3}$ and $\mathrm{SrSO}_{4}$ in the outer corrosion products is generally ascribed to the high scaling sensitivity of the formation water which containing high concentrations of $\mathrm{Ca}^{2+}, \mathrm{Mg}^{2+}$ and $\mathrm{Sr}^{2+}$ (shown in Table 3). The formation of iron oxides in the internal corrosion products is usually related to the corrosion during the later transporting process where the wet internal surface was exposed to air and formed iron oxides.

Table 3. Chemical compositions of the formation water

\begin{tabular}{|c|c|c|c|c|c|c|c|c|c|}
\hline Component & $\mathrm{Cl}^{-}$ & $\mathrm{HCO}_{3}^{-}$ & $\mathrm{SO}_{4}^{2-}$ & $\mathrm{K}^{+}$ & $\mathrm{Na}^{+}$ & $\mathrm{Ca}^{2+}$ & $\mathrm{Mg}^{2+}$ & $\mathrm{Sr}^{2+}$ & $\mathrm{Ba}^{2+}$ \\
\hline Content $(\mathrm{g} / \mathrm{L})$ & 111 & 0.03 & 0.27 & 1.84 & 56.71 & 11.31 & 0.94 & 0.46 & 0.007 \\
\hline
\end{tabular}

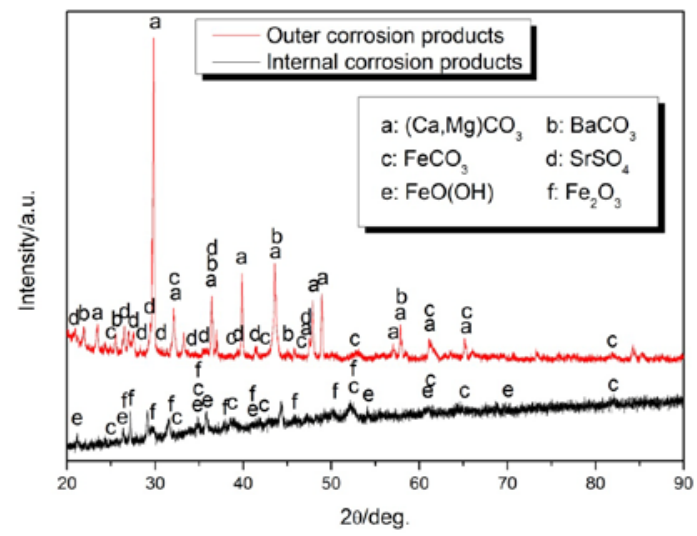

Figure 8. XRD spectrum diagrams of the corrosion products

\section{Failure mechanism analysis}

During the service period, this pipeline was utilized to transport wet gas. According to the service conditions listed in Table 4, the internal medium possesses high content of water $(84.23 \%)$ and corrosive acid gas $\left(0.906 \% \mathrm{CO}_{2}\right.$ and $\left.0.013 \% \mathrm{H}_{2} \mathrm{~S}\right)$. As mentioned above, high contents of $\mathrm{Ca}^{2+}, \mathrm{Mg}^{2+}$ and $\mathrm{Sr}^{2+}$ in the formation water show high trend to form scaling deposit (i.e. $\mathrm{CaCO}_{3}$ and $\mathrm{SrSO}_{4}$ ).

Table 4. Service conditions of the studied carbon steel pipeline

\begin{tabular}{|c|c|}
\hline Parameters & Value \\
\hline Temperature & $49{ }^{\circ} \mathrm{C}$ \\
\hline Pressure & $1.5 \mathrm{MPa}$ \\
\hline Water content & $84.23 \%$ \\
\hline Flow rate & $1.4 \mathrm{~m} / \mathrm{s}$ \\
\hline $\mathrm{H}_{2} \mathrm{~S}$ content in gas & $0.013 \%$ \\
\hline $\mathrm{CO}_{2}$ content in gas & $0.906 \%$ \\
\hline
\end{tabular}


From the above discussions, it is possible to infer that the reason of the studied carbon steel pipe suffered the severe local corrosion was mainly the interaction of the associated gas $\mathrm{CO}_{2}$ and formation water. $\mathrm{FeCO}_{3}$ in the corrosion deposits were formed from $\mathrm{CO}_{2},(\mathrm{Ca}, \mathrm{Mg}) \mathrm{CO}_{3}$ and $\mathrm{SrSO}_{4}$ in the scaling deposit were formed from the formation water.

Research indicates that at temperatures below $60{ }^{\circ} \mathrm{C}$, the iron carbonate $\left(\mathrm{FeCO}_{3}\right)$ product film formed by corrosion is thick, but loose, and not dense, and does not prevent further corrosion. In addition, $\mathrm{CO}_{2}$ corrosion increases with velocity of flow. The rate of corrosion increases $\sim 68 \%$ as the velocity of flow increases from 0.1 to $1.0 \mathrm{~m} / \mathrm{s}$ [4]. From this perspective, the low service temperature and high flow rate in the present work would lead to a rapid formation of loose iron carbonate layer.

In the present work, the service temperature of the studied carbon steel pipeline was $49{ }^{\circ} \mathrm{C}$, and the flow velocity was $1.4 \mathrm{~m} / \mathrm{s}$. During the initial service period, iron carbonate film formed as the $\mathrm{CO}_{2}$ corrosion products. Because the iron carbonate film formed at temperatures below $60{ }^{\circ} \mathrm{C}$ is loose and rough, so that the formation water could go through the loose and porous scale and arrived at the surface of the matrix, and the electrochemical reactions took place subsequently. At the same time, scaling deposits such as $(\mathrm{Ca}, \mathrm{Mg}) \mathrm{CO}_{3}$ and $\mathrm{SrSO}_{4}$ deposited on the outer rough surface.

The possible mechanism of the corrosive perforation is as follows.

First, the associated gas $\mathrm{CO}_{2}$ dissolved in formation water and carbonic acid was formed (Eq. (1)), which corroded the carbon steel. As a weak acid, carbonic acid partially dissociates into hydrogen ions and bicarbonate ions (Eq. (2)), which is followed by the dissociation of bicarbonate ions that form additional hydrogen ions and carbonate ions (Eq. (3)). Hydrogen ions are reduced at the steel surface to form hydrogen gas by Eq. (4). In addition to the reduction of hydrogen ions, it is often assumed that carbonic acid is directly reduced at the metal surface by Eq. (5). Surface iron atoms, give up electrons and dissolve into the aqueous solution to produce ferrous ions by Eq. (6), resulting steel corrosion [5]. When steel corrodes, it releases $\mathrm{Fe}^{2+}$ ions which accumulate in the solution. When their concentration reaches and exceeds the saturation level, iron carbonate will precipitate according to Eqs. (7) - (9) [6-7].

$$
\begin{gathered}
\mathrm{CO}_{2}+\mathrm{H}_{2} \mathrm{O} \rightarrow \mathrm{H}_{2} \mathrm{CO}_{3} \\
2 \mathrm{H}_{2} \mathrm{CO}_{3}+2 \mathrm{e} \rightarrow \mathrm{H}_{2}+2 \mathrm{HCO}_{3}^{-} \\
2 \mathrm{HCO}_{3}^{-}+2 \mathrm{e} \rightarrow \mathrm{H}_{2}+2 \mathrm{CO}_{3}^{2-} \\
2 \mathrm{H}^{+}+2 \mathrm{e} \rightarrow \mathrm{H}_{2} \\
2 \mathrm{H}_{2} \mathrm{CO}_{3}+2 \mathrm{e} \rightarrow \mathrm{H}_{2}+2 \mathrm{HCO}_{3} \\
\mathrm{Fe} \rightarrow \mathrm{Fe}^{2+}+2 \mathrm{e} \\
\mathrm{Fe}^{2+}+\mathrm{CO}_{3}^{2-} \rightarrow \mathrm{FeCO} \\
\mathrm{Fe}^{2+}+2 \mathrm{HCO}_{3}^{-} \rightarrow \mathrm{Fe}\left(\mathrm{HCO}_{3}\right)_{2} \\
\mathrm{Fe}\left(\mathrm{HCO}_{3}\right)_{2} \rightarrow \mathrm{FeCO}_{3}+\mathrm{CO}_{2}+\mathrm{H}_{2} \mathrm{O}
\end{gathered}
$$

Second, the loose and porous iron carbonate layer made the deposition of scaling deposits on the outer rough surface possible. Scaling deposits may from in following ways (Eqs. (10)-(11)).

$$
\begin{gathered}
\mathrm{Ca}^{2+}+\mathrm{CO}_{3}{ }^{2-} \rightarrow \mathrm{CaCO}_{3}+\mathrm{CO}_{2}+\mathrm{H}_{2} \mathrm{O} \\
\mathrm{Sr}^{2+}+\mathrm{SO}_{4}{ }^{2-} \rightarrow \mathrm{SrSO}_{4}
\end{gathered}
$$

Third, formation water could go through the loose and porous iron carbonate layer, arrive at the surface of matrix, and cause further corrosion.

Fourth, the localized corrosion may be related to the failure of iron carbonate layer and/or scaling deposit layer. The scale deposit layer seems be detached from the outer surface layer by layer as mentioned in Figure 3. In the formation water, the high concentration of chloride ions $(\sim 111 \mathrm{~g} / \mathrm{L})$ 
could cause the initiation of localized corrosion possibly by changing the solubility of iron carbonate [8]. When an initiation process occurred that would partially damage the iron carbonate layer and/or scaling deposits layer to leave a small bare steel area coupled with the larger iron carbonate covered surface area, the localized corrosion would propagate and grow [9]. With the pitting deepening and widening, carbon steel pipe would undergo corrosion perforation eventually.

\section{Conclusions}

Based on the above results and discussions, the internal corrosion of the studied carbon steel pipe is ascribed to the corrosive $\mathrm{CO}_{2}$ gas and the high content of formation water in the internal transporting medium. At the relatively low service temperature, loose and porous iron carbonate layer initially formed and the rough surface made the deposition of scale deposits (i.e. $(\mathrm{Ca}, \mathrm{Mg}) \mathrm{CO}_{3}$ and $\left.\mathrm{SrSO}_{4}\right)$ possible. Corrosive medium went through the loose and porous iron carbonate layer and/or localized scale deposits, arrived at the surface of the metal matrix, and then induced further corrosion. With time elongated, the thick scaling deposit layer was pat to drop locally. The high concentration of chloride ions in the formation water caused the initiation of localized corrosion possibly by changing the solubility of iron carbonate, and then the localized corrosion pit propagated and eventually caused the perforation.

\section{Suggestions}

Considering the highly corrosive medium and high scaling sensitivity of the formation water in the pipeline, it is necessary to add scale-corrosion inhibitors into the pipeline continuously to retard the occurrence of corrosion perforation. In order to promote the efficiency of scale-corrosion inhibitor, regular pipeline pigging process and pretreatment of corrosion inhibitor is required.

\section{References}

1. A.Q. Fu, Y.R. Feng, R. Cai, J.T. Yuan, C.X. Yin, D.M. Yang, Y. Long, Z.Q. Bai. Eng. Fail. Anal. 66, 566 (2016)

2. Y. Liu, Y. Zhang, J. Yuan, M. Ye, J. Xu. Eng. Fail. Anal. 34, 25 (2013)

3. L. Shi, C. Wang, C. Zou. Eng. Fail. Anal. 36, 372 (2014)

4. S. Lu, J. Xiang, Y. Kang, Z. Chang, X. Dong, T. Zhai. Mater. Performance 47, 66 (2008)

5. T. Tran, B. Brown, S. Nesic. NACE CORROSION CONFERENCE, paper No. 5671 (2015)

6. T. Tanupabrungsun, B. Brown, S. Nesic. NACE CORROSION CONFERENCE, paper No. 2348 (2013)

7. J. K. Heuer, J. F. Stubbings. Corros. Sci. 41, 1231 (1999)

8. X. Gao, B. Brown, S. Nesic. NACE CORROSION CONFERENCE, paper No. 3880 (2014)

9. J. Han, B. N. Brown, S. Nesic. Corrosion 66, 095003-1 (2010) 